\title{
The use of Educational Media and Technology on Book Content Preservation: The Case Study on Wong-Yao Educational Cartoon Series
}

\author{
Perng Jeu Ng \\ Dept. of Multimedia Design and Animation \\ Universiti Tunku Abdul Rahman \\ Kuala Lumpur, Malaysia \\ perngjeu@gmail.com
}

\author{
Mohd Fairuz bin Ali \\ Dept. of Multimedia Design and Animation. \\ Universiti Tunku Adbul Rahman \\ Kuala Lumpur, Malaysia \\ fairuza@utar.edu.my
}

\begin{abstract}
Nowadays, the exponential growth of media and technology usage in education, through variety type of platform has raise significantly the focus and importance of educational media research. In this paper, the purpose is to find out the impact of using multimedia on transforming and preserving traditional reading content to digital media format. Media are means for transferring or delivering certain messages to audience, media is important and it is impossible to generate learning desire without using media. Educational media aims on encourage readers to take more responsibility and self-control on their own learning. This study was an investigation of child readers' views on the use of educational media and technology, during reading a series of educational cartoon series in digital format in which transform from a book format. Findings indicated that readers appreciated the benefits of education media in learning progress.
\end{abstract}

Keywords: educational media and technology, digital media, media literacy, content analysis, education

\section{INTRODUCTION}

Educational media and technology no longer needs to prove its efficiency in learning process, many schools and universities have proceeded in using elearning and computer in education. Several studies have been performed to examine the effectiveness of different types of e-learning and usage computer in education in acquisition and enhance student's skills and increase the effectiveness of their achievement capabilities. The current research only in conscious response to the necessities of use of new types of educational technologies, in order to increase the effectiveness of the learning process, which is considered as a requirement to achieve distinctive growth in learning based modern technologies and tools. Hence, emerges the importance of the current research which aims to measure the effect of interactive e-book on learners' achievement at learning. With the emergence of educational technologies, with believing in the importance of the diversity of methods of providing information and its effect on increasing student achievement, the e-book emerges as one of the modern technology emergencies in introducing econtent in a more attractive and interactive manner which has never been seen before through the traditional printed book. E-book industry made it easy to exchange information and data via the internet and mobile phones, and emerges a new type of learning which is referred to mobile learning, Books are considered the most important tool used to transfer knowledge and assess information and academic educational program since the invention of the printing machine. With the development of the means of electronic publishing, globalized information, and easy access via internet, e-book became the more advanced tool used to transfer knowledge [1].

\section{LITERATURE REVIEW}

\section{A. Interactive Book and Multimedia}

An e-book is an "integration of the classical print structure with an electronic environment giving additional value added features that paper cannot provide" [2]. Some of the advantages are timely and cost efficient distribution; the ability to search and interact with the text easily; and widespread accessibility through the Internet [3][4]. With a desktop PC, the e-book is not as portable as its print counterpart, but with technological developments resulting in increasingly lightweight computers this is changing. The benefits that dedicated hand held devices introduce to reading. In addition to those already mentioned, these include: mobile access to large amounts of information; organizing e.g. by annotating; filtering by generating personalised queries; and support for different modes of reading. Some of these advantages can be obtained, when using e-books with other types of hardware, through the use of special reader software.

\section{B. The Roles of Digital Narrative}

The way of information shared to the community has evolve dramatically over the years. Through the timeline we could see the digital age has influence people's life in choosing their way to engage with information and can be seen to becoming more popular. According to a data released by PubTrack Digital, traditional publishers have made 162 million from the eBook sales last year in 2017[5].

The role of digital narrative has significantly impacted richly the way human interact with digital contents. Take Interactive Digital Narrative as an example. IDN aggregates different artistic and research directions from malleable, screen-based textual representations to the quest for virtual spaces in which human interactors experience coherent narratives side by side with authored narrative elements and synthetic characters. The IDN vision is as much about narrative and control. Clearly 
digital media has radically changed the way narrative content is being created, shared, and experienced and interpreted [6].

\section{Existing eBook Samples}

The nature of change of books presented in new media and digital technology has taken place. With the Internet in power such contexts could be delivered in a global scale. Below are the examples of eBook platforms that could be found over the internet targeting groups ranging from kids, teenagers and to adults.

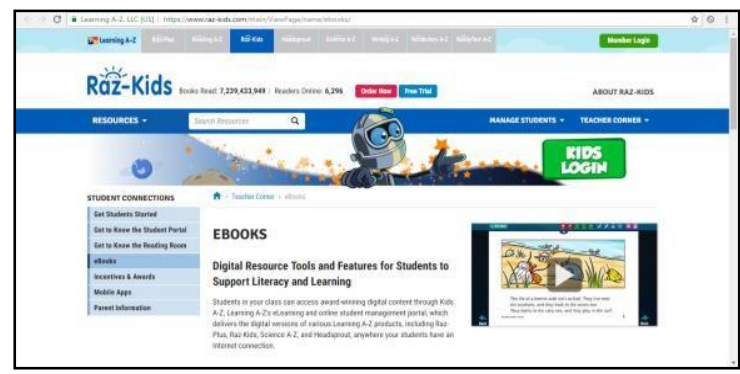

Figure 1. www.raz-kids.com

Raz-Kids offer hundreds of eBooks which allowing user to engage with the interactive multimedia contents such as video, audio and audio recording for reading level. This platform is targeting K-5 age group (Kindergarten to standard 5) in American education term.

Similar approach can be found through a Website called Lilfingers as they are offering interactive eBooks focusing on early reading level for kids. User just need to select the book from the set and start interacting with it. The interactions covered with narration audio and tied with cute visuals and interesting short storyline. Other multimedia contents such as online digital games and videos can also be found in this Website.

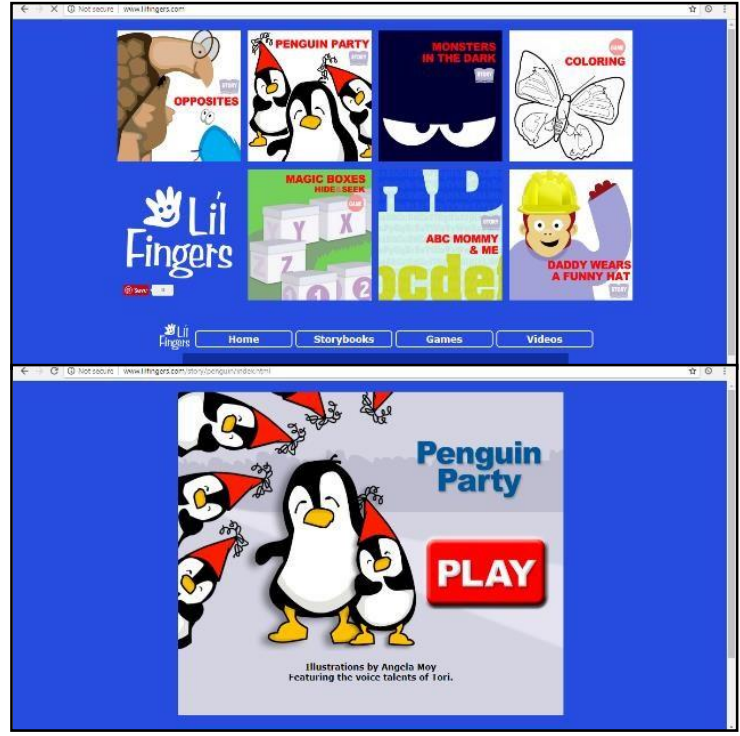

Figure 2. http://www.lilfingers.com

A platform such as EpicReads on the other hands are aiming target group from teen to adults. It serves as a community for readers to find the latest and hottest eBooks in store. The platform is made well engaging with the users as they are actively making use of social media like Twitter, Facebook, Youtube, Instagram and other social media platforms effectively to reach out to their new and existing users.

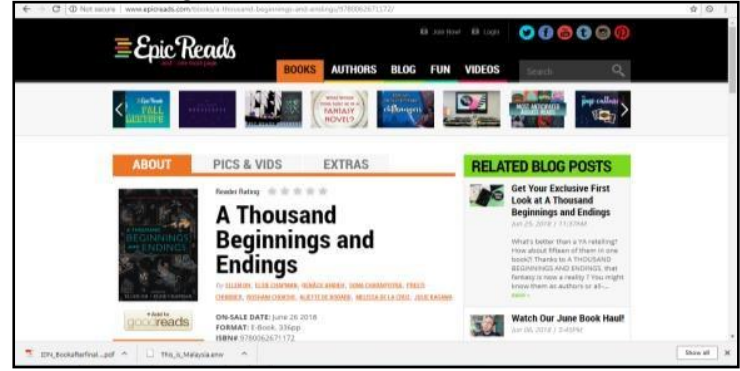

Fig 3. http:/ /www.epicreads.com

\section{Huang Yao}

Though they were widely enjoyed, the cartoons of the 1930s were not just for entertainment, wrote art critic Jack Chen. These were socio-political commentaries in a humorous vein. They often exposed corruption or satirized contemporary life and society, advocating democracy and criticizing old feudal ways. In fact, they quickly became important social commentaries, and the cartoonists are rightly viewed today as key figures in helping historians document the period. Cartoon art was the contemporary art of that era.

At the same time, Shanghai was experiencing an influx of foreign products and culture, especially from America. Mickey Mouse, Donald Duck and Popeye were dominating the cultural milieu and Huang Yao in particular was determined to create something purely Chinese to prevent the domination of foreign influence.

While US cartoons of the same period often depicted heroes with supernatural powers - social activists shaking off their human weaknesses during Depression- era America - Huang Yao's cartoons portrayed the everyman. In his appear- ance, his attitude and his sense of humor, Niubizi had thoroughly Chinese characteristics. At his core, Niubizi was humorous and courageous: an image of the common man calling for selfrespect and independence for his nation and people. Niubizi's adventures were also typically Chinese, appealing directly to the cartoon's local audience. His If I Were... series saw Niubizi transformed into the Monkey King, a Ming Emperor and a host of other historical and mythical Ghinese figures.

\section{METHODOLOGY}

More specifically, the following research questions can be addressed to support the research objectives:

i) What suitable approach designs are required to advance the interactivity process with users' expectations?

ii) How different were users' experiences with the Multimedia Platform compare to traditional platform?

Table 1. Research Questions and Data Collection Instruments

\begin{tabular}{|c|c|c|}
\hline & $\begin{array}{l}\text { Research Questions and } \\
\text { Hypotheses }\end{array}$ & $\begin{array}{l}\text { Data Collection } \\
\text { Instruments }\end{array}$ \\
\hline i) & $\begin{array}{l}\text { What suitable approach designs } \\
\text { are required to advance the } \\
\text { interactivity process with users' } \\
\text { expectations? }\end{array}$ & 1. Questionnaire \\
\hline ii) & $\begin{array}{l}\text { How different were users' } \\
\text { experiences with the } \\
\text { Multimedia Platform compare } \\
\text { to traditional platform? }\end{array}$ & $\begin{array}{l}\text { 1. Questionnaire and } \\
\text { Observation }\end{array}$ \\
\hline
\end{tabular}




\section{RESULTS OF FINDINGS}

Overall, a total of forty participants participated in this study. In order to have the most accurate results, participants were based on an early reader demographic. Participants volunteered at random and did not have any known prior association with the eBook chosen for the study. In addition, participants needed to have a signed parental consent form in order to participate in the study. Participants were asked to participate during the reading and language hour of their school day so as to not disrupt the regular schedule of their learning environment.

The main elements for this case study include the following list: 1.) Response - the main character of this eBook asks the readers to respond verbally at many times during the text. Response, while not a physical interaction is listed due to the cognitive impact suggested with this interaction. 2.) Sound - for this eBook, sound represents the music, effects and narration showcased in the eBook. 3.) Animation - this eBook does not include animation that can be altered by the participant, however animation is shown as a result of the participant interacting with the eBook to further the story.

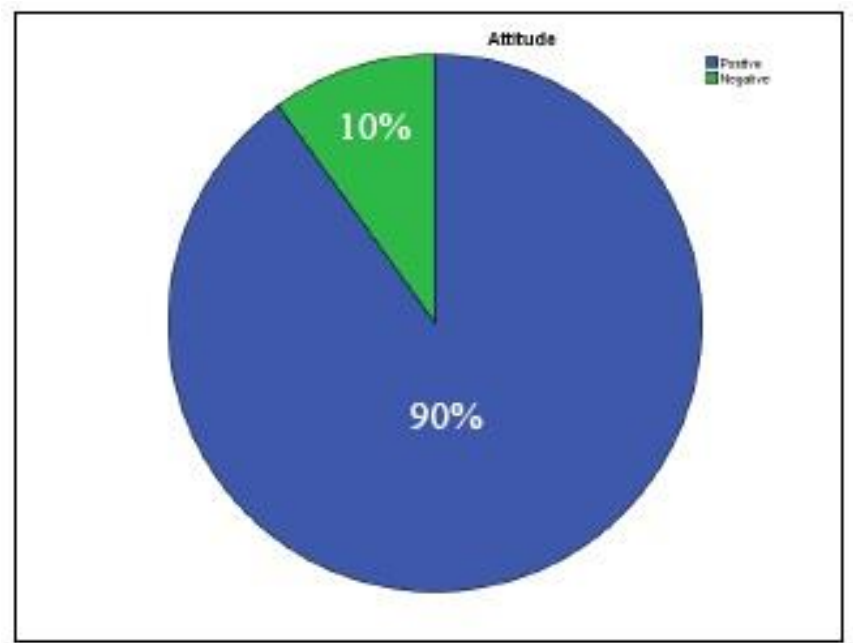

Fig. 4. Initial Reactions Toward Interactive Multimedia Book

Overall, $90 \%$ of participants reacted positively to the eBook with little to no confusion as to how to navigate all interactive elements associated with the eBook. The remaining $10 \%$ of participants responded with initial confusion over how to use basic eBook techniques such as gestures and touch interaction.

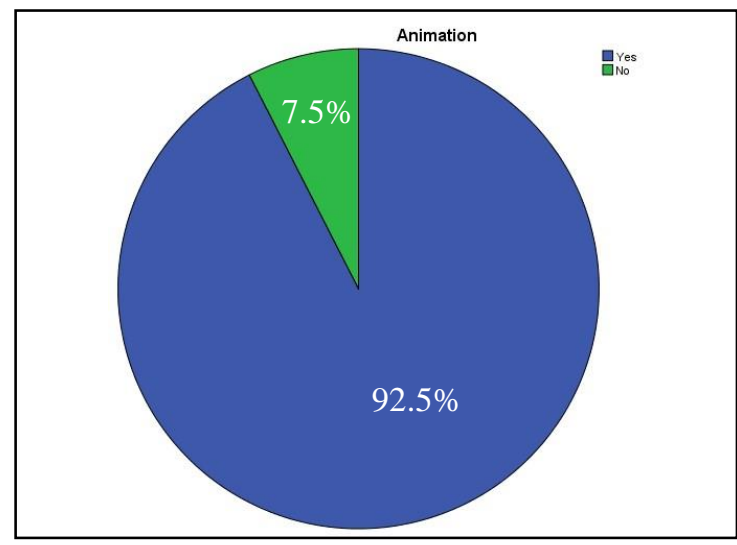

Fig. 5. The Importance of Animation On Interactive Multimedia Book

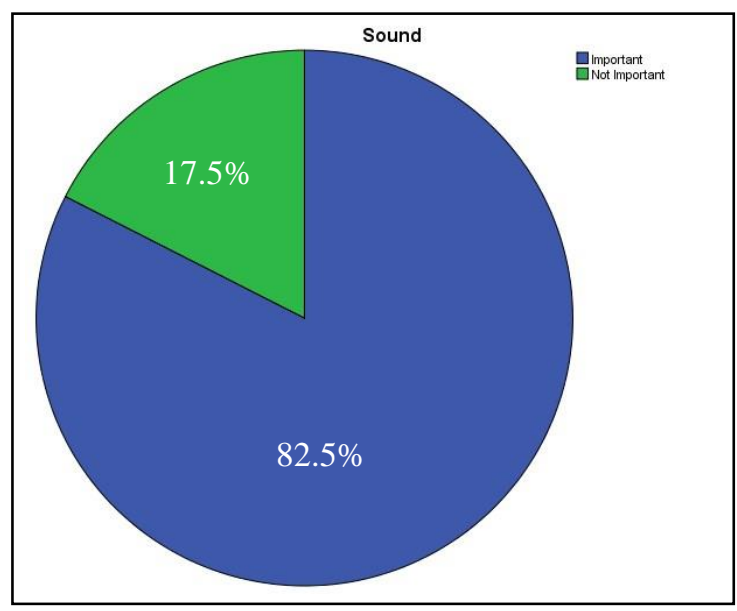

Figure. 6. The Importance of Sound On Interactive Multimedia Book

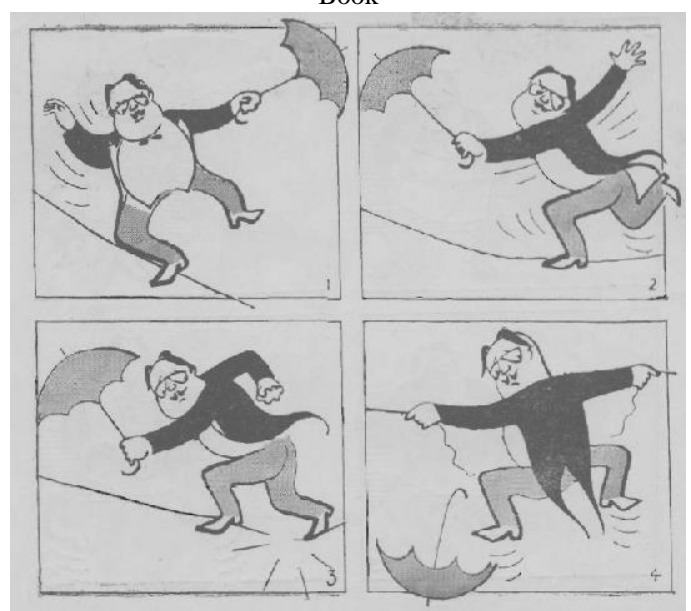

Fig. 7. The Original Illustration Of Wong Yao 


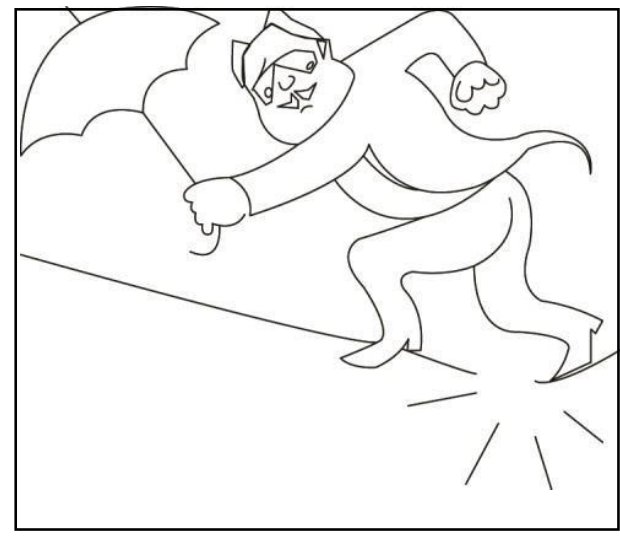

Fig. 8. Art Line for Reproduce in Digital Format

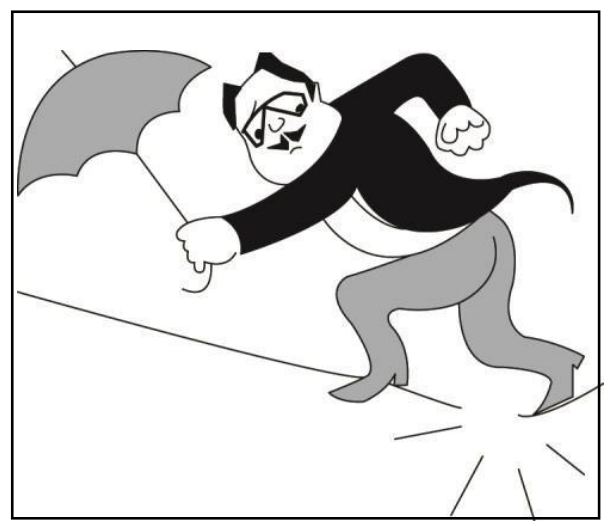

Fig. 9. Applicationof Base Color

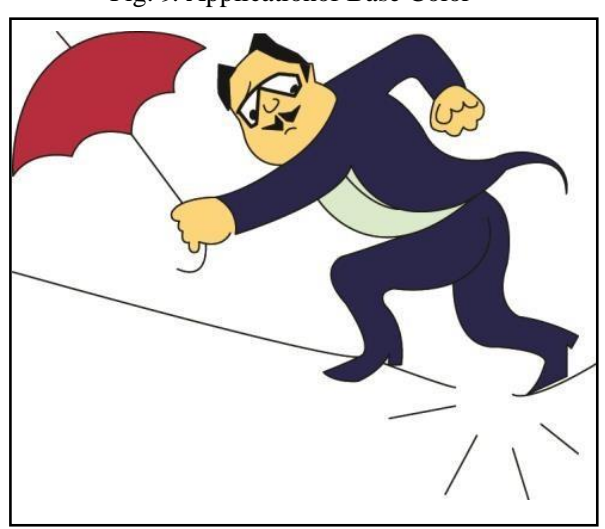

Fig. 10. Application of Full Color for Interactive Multimedia

\section{CONCLUSION}

This This study provides a solid base and stepping point for future studies in eBook interactive elements. The field study suggests more research is needed to define the different types of engagement. This study began a discussion in digital literacy, user experience and design practices for interactive eBooks. This study did not propose a direct conclusion for these areas due to the fact that much more research is needed in all three areas of interest. In the future, more studies may be executed in order to gain a more defined understanding of interactive elements in eBooks.

\section{ACKNOWLEDGMENT}

Thanks to research partner Mr. Fairuz Ali on providing useful information and guidance

\section{REFERENCES}

[1] Chen, Y. "Application and development of electronic books in an e Gutenberg Age", Online Information Review 27, 1-16. 2002.

[2] Landoni, M., Wilson, R. \& Gibb, F. "From the Visual book to the WEB book: The importance of design." The Electronic Library 18(6), pp.407-419 (online). Web. 2000.

[3] Lynch, C. "Electrifying the book." Library Journal (Oct 15), pp.3-6 (online). Web. 1999.

[4] Schilit, B. (1999). "Why e-read? Finding opportunites in the merger of paper and computers." Future of Print Media Journal (Spring), (online). Web. 1999.

[5] E-book Market Share Worldwide, https://www.statista.com/statistics/234106/e-book-marketshareworldwide/

[6] Taylor \& Francis, Learning Through Interactive Digital Narratives, Routledge, 2015. 